\title{
Pre-Operational Safety Appraisal Tritiated Scrap Recovery Facility Mound Facility
}

J. J. Dauby, T. M. Flanagan,

L. W. Metcalf and T. B. Rhinehammer

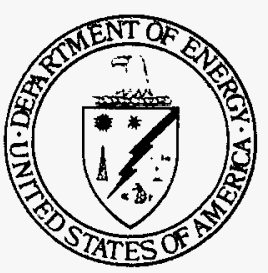

MOUND FACILITY

Miamisburg, Ohio 45342

Monsanto

operated by

MONSANTO RESEARCH CORPORATION

a subsidiary of Monsanto Company

for the

U. S. DEPARTMENT OF ENERGY

Contract No.DE-ACO4-76-DPDOD53

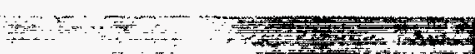

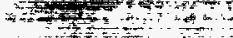

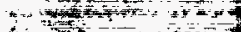

$+\frac{1}{2}+x$

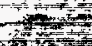

A 
5. Accident Analysis 17

5.1 Introduction $\quad 17$

5.2 Operational Accident 17

5.2.1 Fire-Design Basis Accident 17

5.2.2 Explosion $\quad 18$

5.2 .3 Power Loss . . . . 19

5.3 Natural Phenomenon. 19

5.3.1 Earthquake 19

5.3 .2 Tornado $\quad 20$

6. Conclusions 24

\section{DISCLAIMER}

This report was prepared as an account of work sponsored by an agency of the United States Government. Neither the United States Government nor any agency thereof, nor any of their employees, makes any warranty, express or implied, or assumes any legal liability or responsibility for the accuracy, completeness, or usefulness of any information, apparatus, product, or process disclosed, or represents that its use would not infringe privately owned rights. Reference herein to any specific commercial product, process, or service by trade name, trademark, manufacturer, or otherwise does not necessarily constitute or imply its endorsement, recommendation, or favoring by the United States Government or any agency thereof. The views and opinions of authors expressed herein do not necessarily state or reflect those of the United States Government or any agency thereof. 


\section{PREOPERATIONAL SAFETY APPRAISAL}

PROJECT DESCRIPTION $\frac{\text { Tritiated Scrap Recovery Facility, }}{\text { Mound Facility }}$

PROJECT DIRECTIVE NUMBER None

PROJECT HAZARD LEVEL

\section{SAFETY AUTHORIZATION}

$\frac{\text { Hon Ething } 11 / 10 / 81}{\text { mate }}$

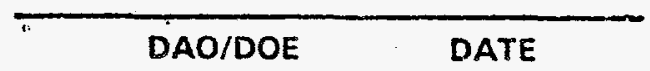

BASIS FOR AUTHORIZATION Loss Prevention and

Environmental Control Process Review

COMMENT

None 


\section{DISCLAIMER}

Portions of this document may be illegible in electronic image products. Images are produced from the best available original document. 
PRE-OPERATIONAL SAFETY APPRAISAL-TRITIATED SCRAP

Startup Recommended by:

f. Daby

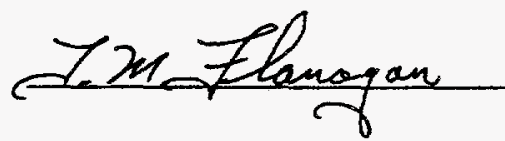

J. J. Dauby, Senior Research Chemist, Recovery Operations, Monsanto Research Corporation

T. M. Flanagan, Senior Engineer, Systems Safety Group, Monsanto Research Corporation

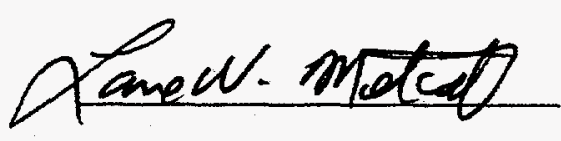

L. W. Metcalf, Supervisor, Systems Safety Group, Monsanto Research Corporation

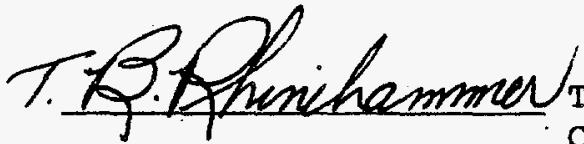

T.

Component Development, Monsanto Research

Corporation 


\section{SUMMARY}

The Tritiated Scrap Recovery Facility will provide capabilities for the processing of solid and gaseous waste to recycle a strategic and valuable resource, tritium. The new facility has incorporated the state-of-the-art technology related to the safety of operating personnel, the general public and the environment. Analysis of the Design Basis Accident indicates that no Federal standards will be exceeded. The overall hazard level of this facility is low. This project does not pose any greater risks to the operating personnel, members of the general public or the environment than are currently accepted. 
The purpose of this report is to identify, assess, and document the hazards which are associated with the proposed operation of the Tritiated Scrap Recovery Facility at Mound Facility. A Pre-operational Safety Appraisal is a requirement as stated in Department of Energy Order 5481.1, Safety Analysis and Review System. The operations to be conducted in the new Tritiated Scrap waste Recovery Facility are not new, but a continuation of a prime mission of Mound's i.e. recovery of tritium from waste produced throughout the DOE complex. The new facility is a replacement of an existing process started in the early 1960 's and incorporates numerous design changes to enhance personnel and environmental safety. This report also documents the safety of a one time operaation involving the recovery of tritium from material obtained by the Department of Energy from the State of Arizona. This project will involve the processing of 240,000 curies of tritium contained in glass ampoules that were to be used in items such as luminous dial watches. These were manufactured by the now defunct American Atomics Corporation, Tucson, Arizona. 


\section{DESCRIPTION OF BUILDING}

The Tritiated Waste Recovery Facility is located in an existing radioactive material processing area, the Research Building ( $R$ Bldg.). Figure 3-1 shows the location of the R-Bldg. at Mound Facility. The new facility is located in $R-108$ as shown in Figure 3-2. The area north of column line 2 is an existing tritium processing area of the R-Bldg. The Semi-Works Building (SW Bldg.) is west of Column $M$ and is Mound's major tritium processing building. Many support systems such as an Effluent Removal system (ERS) are located in the SW-Bldg, and will be utilized by the R-108 operations.

The original R-Bldg. is a one story building with a second floor penthouse constructed of a monolithic slab and joist system supported by beams spanning between building columns. The building is founded with spread footings on limestone and shale. The exterior column footings are tied together with a perimeter grade beam.

Four additions have been made to the original building. A corrugated metal wall and roof deck structure was added on the south end of the original building. The roof of this addition is framed with light structural steel members supported by square tube columns. Lateral strength is provided by the diaphragm action of the corrugated metal wall and roof panels. Spread footings and a perimeter grade beam support the building addition on limestone and shale.

An addition between the south end of the original R-Bldg. and E-Bldg. is constructed of reinforced masonry exterior walls and is supported by grade beams on drilled caissons to bedrock. A steel-framed penthouse with steel panel siding is located in the northeast corner of this addition. The penthouse floor consists of a poured-in-place reinforced concrete slab supported by steel joists. The roof and penthouse roof are built-up on corrugated metal decking supported by steel joists.

A third addition to the original R-Bldg. is located between the north end of the original building and E-Bldg. The addition consists of a reinforced masonry wall between the existing buildings and a built-up roof on metal deck supported by steel joists spanning between the E-BIdg. and original RBldg. walls. A grade beam supports the structure on lime and shale. An " addition north of the original building consists of masonry bearing walls witr: at metal deck roof. Bearing walls are founded on strip foundations in limestone and shale.

The ventilation system to be used for the R-108 operations is an existing system that also services much of the tritium operations conducted in the sW-Bldg. The system has a High Efficiency Particulate Air (HEPA) filtration capability. The HEPA's will not provide any protection to the environment from the release of tritium, but would stop any particulate such as uranium in the event there was a uranium tritide release.

This facility has incorporated numerous fire protection systems to prevent and mitigate the consequences of a fire. Details are discussed in Section 5.2.1. 


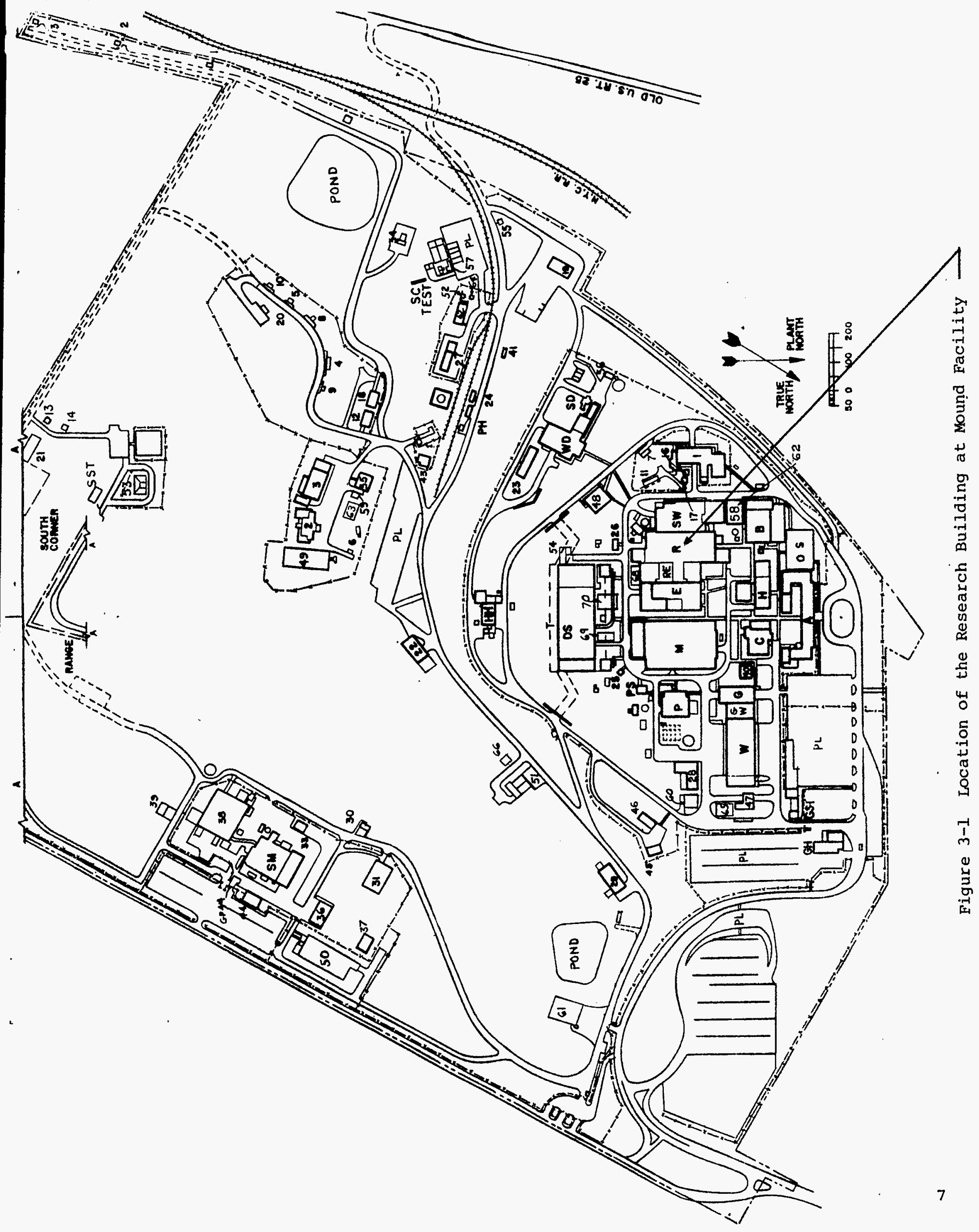




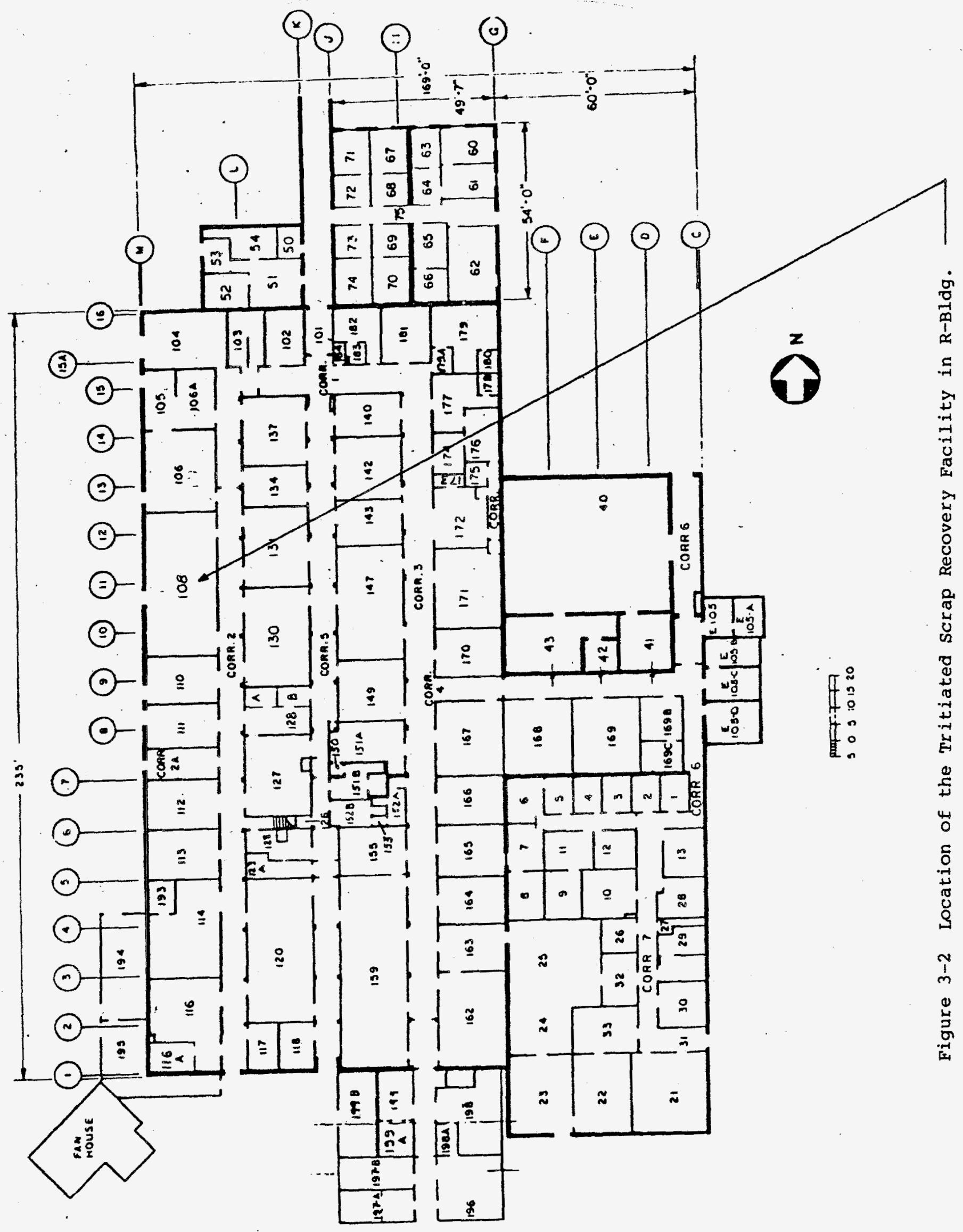


Figure $3-3$ is a room layout of the Tritiated Scrap Recovery Facility. Figure 3-4 is a photograph of the control console. At this console, an operator can determine and control the position of valves (open or closed) tritium concentrations, temperature, and pressure, etc. of critical operations and equipment. Figure $3-5$ is a photograph of the process Hood. This hood contains a nitrogen atmosphere which is slowly purged. Much of the equipment inside, previous to Mound's double containment philosophy, would have been in air ventilated fumehood. Tritium concentration in this system is anticipated to be minor and only elevated during unusual occurrences. This atmosphere would be automatically diverted, by tritium monitors, to the ERS in the event of a tritium release where the tritium would be removed prior to being released to the environment.

The Maintenance Hood, shown in Figure 3-6, is an air atmosphere enclosure normally vented to the stack, but whose flow can be diverted to the ERS. In this area, maintenance on contaminated items can be performed without environmental releases. Major maintenance on systems in the process Hood will also be performed from the Maintenance Hood especially when a hood front has to be removed. Figure 3-7 shows the reactors in the Inert Glovebox. In these reactors, solid tritiated scrap is heated up to $1000^{\circ} \mathrm{C}$. The material decomposed, the hydrogen isotopes transferred to storage tanks and finally on to other purification steps. The atmosphere in this system is of extremely high purity because of the reactivity of some of the waste such as uranium tritide with oxygen or water. The atmosphere will contain tritium but the concentrations will not pose a significant risk to personnel working through the dry box gloves.

This facility will be used to recover approximately 240,000 curies of tritium contained in glass ampoules which were manufactured by Amercian Atomics Corporation of Tucson, Arizona. Thirty-eight 55-gal. drums containing an estimated $6,000,000$ ampoules will be open in the Drumming Hood shown in Figure 3-8. Prior to opening the drum the void space inside will be flushed and the atmosphere monitored until levels are acceptable for the drums to be open. The ampoules will be passed into the Decontam Box and Drum Hood and finally to the Inert Gas Glovebox for processing. The atmosphere in the Drumming Hoods can be diverted to the ERS to protect the environment during the opening procedure. Each drum contains approximately 7000 curies of tritium.

As shown in Figures 3-4 through 3-8, state-of-the-art technology has been incorporated into the design of the Tritiated Scrap Recovery Facility to protect the operating personnel, members of the general public, and the environment. 

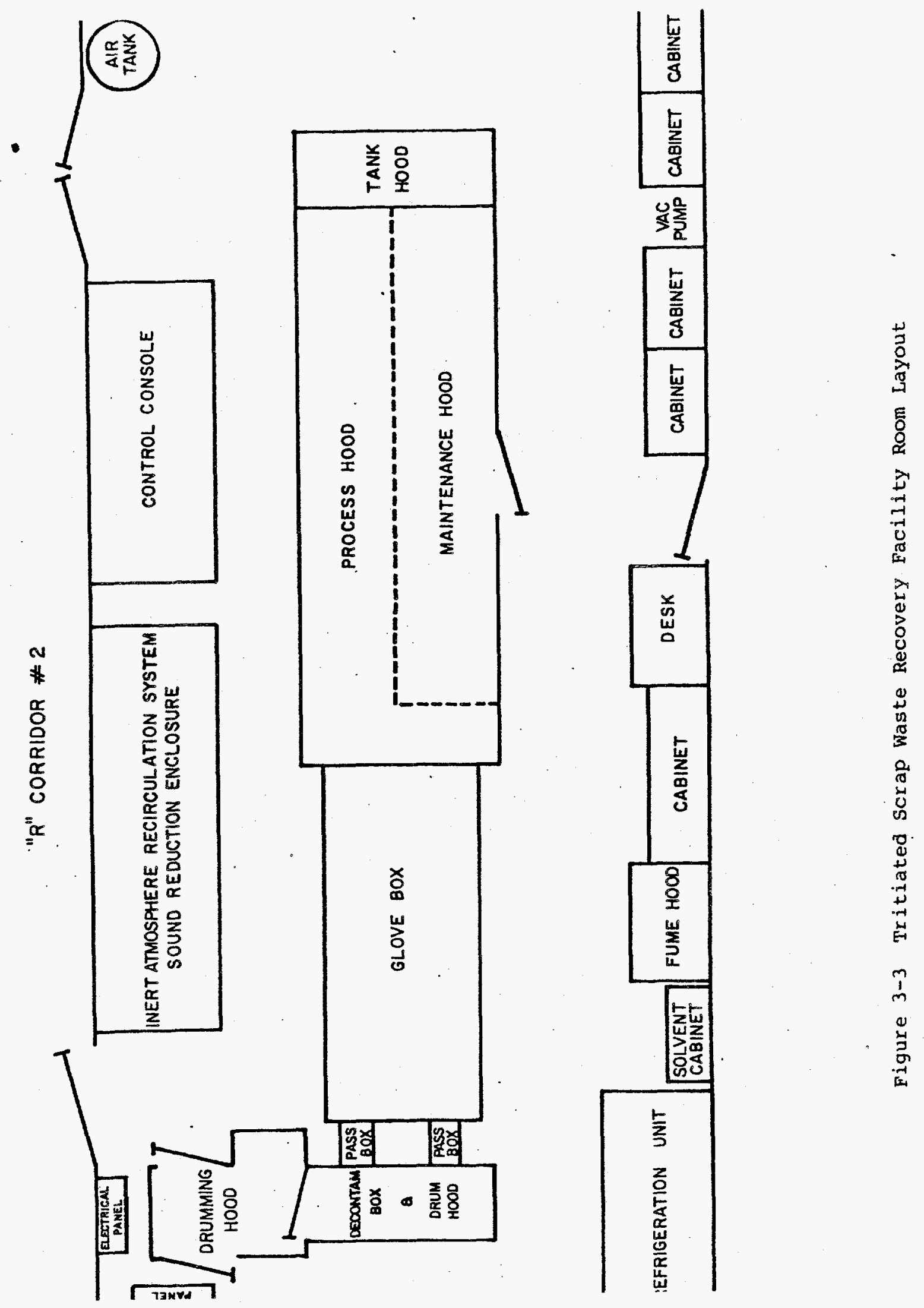


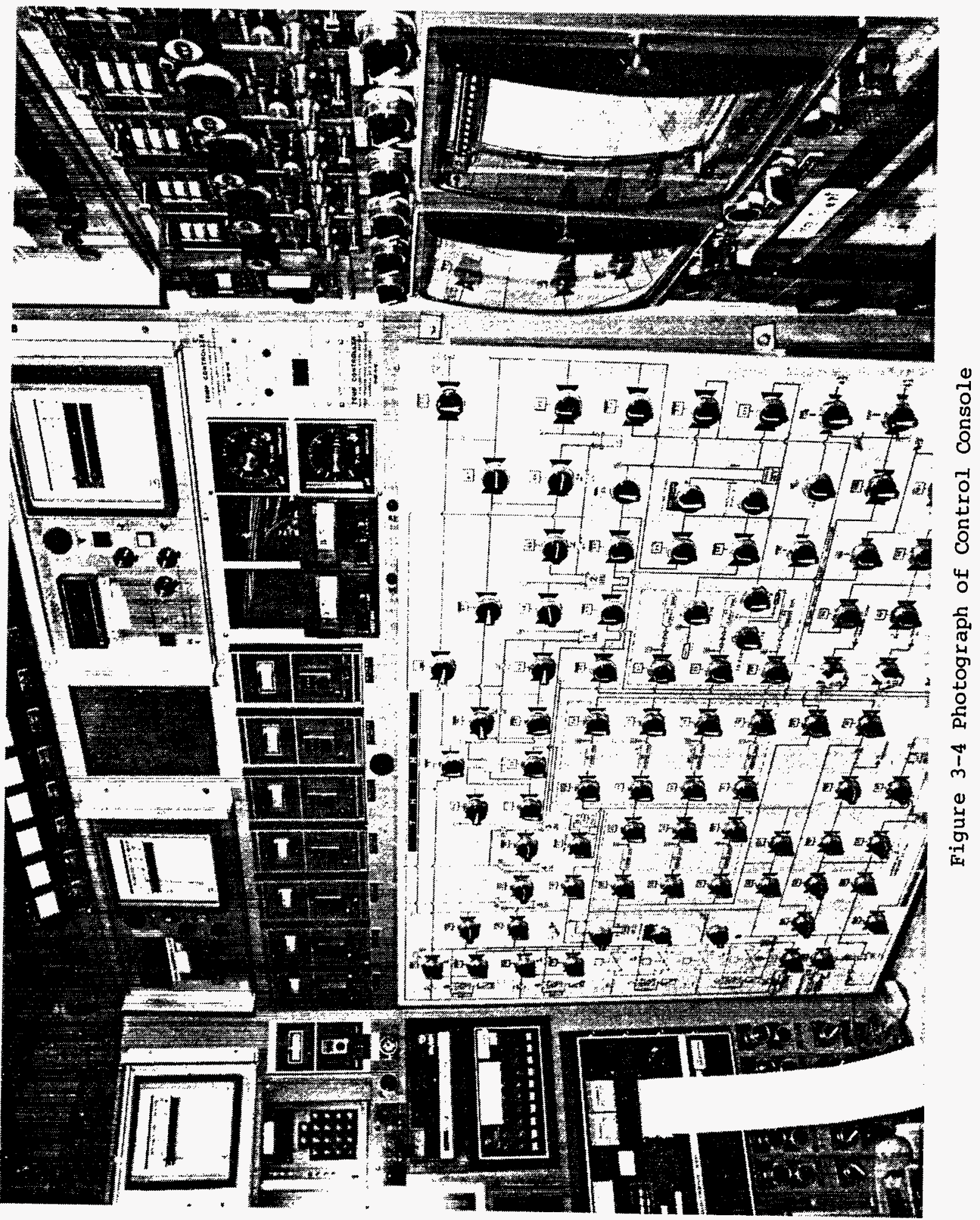




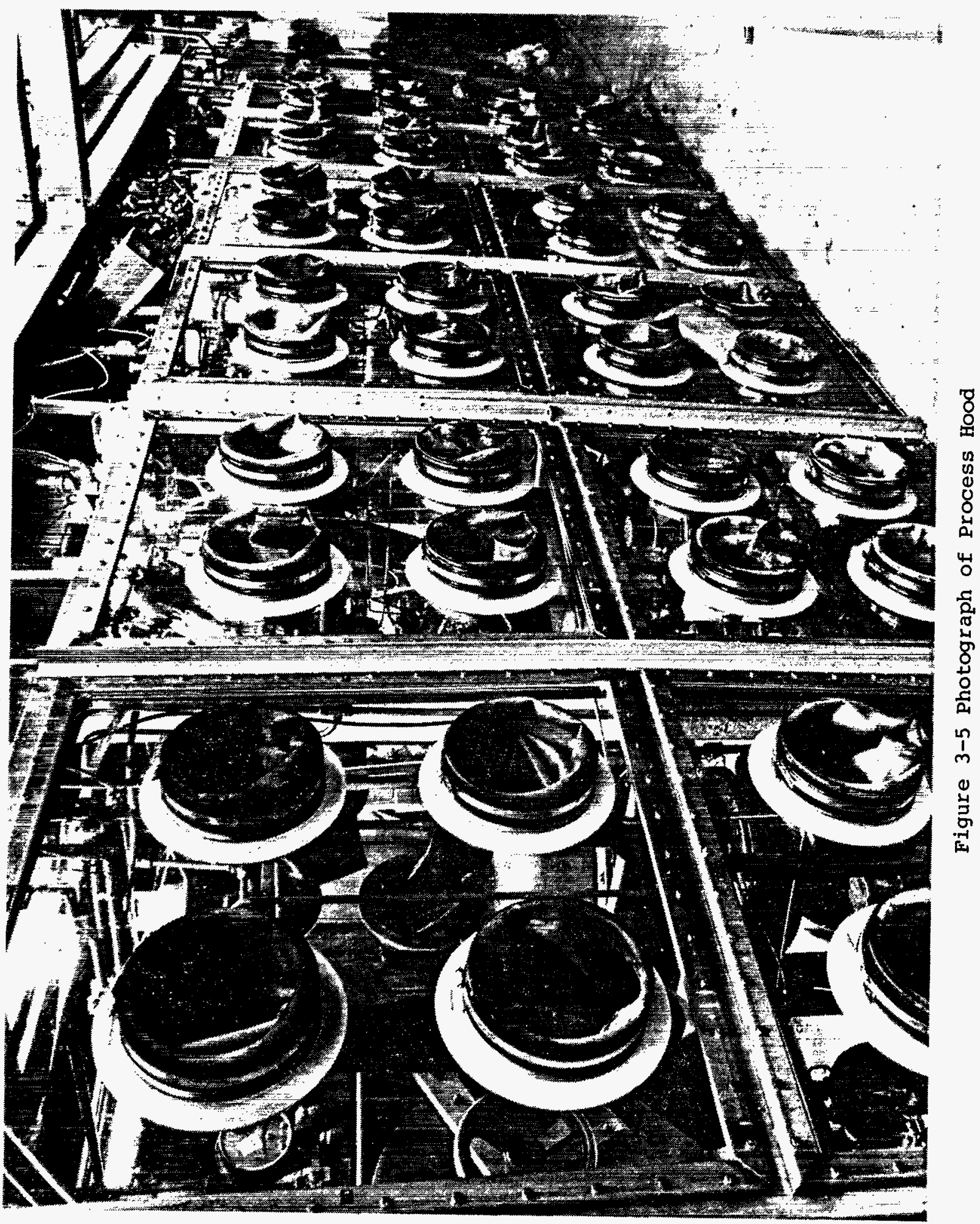




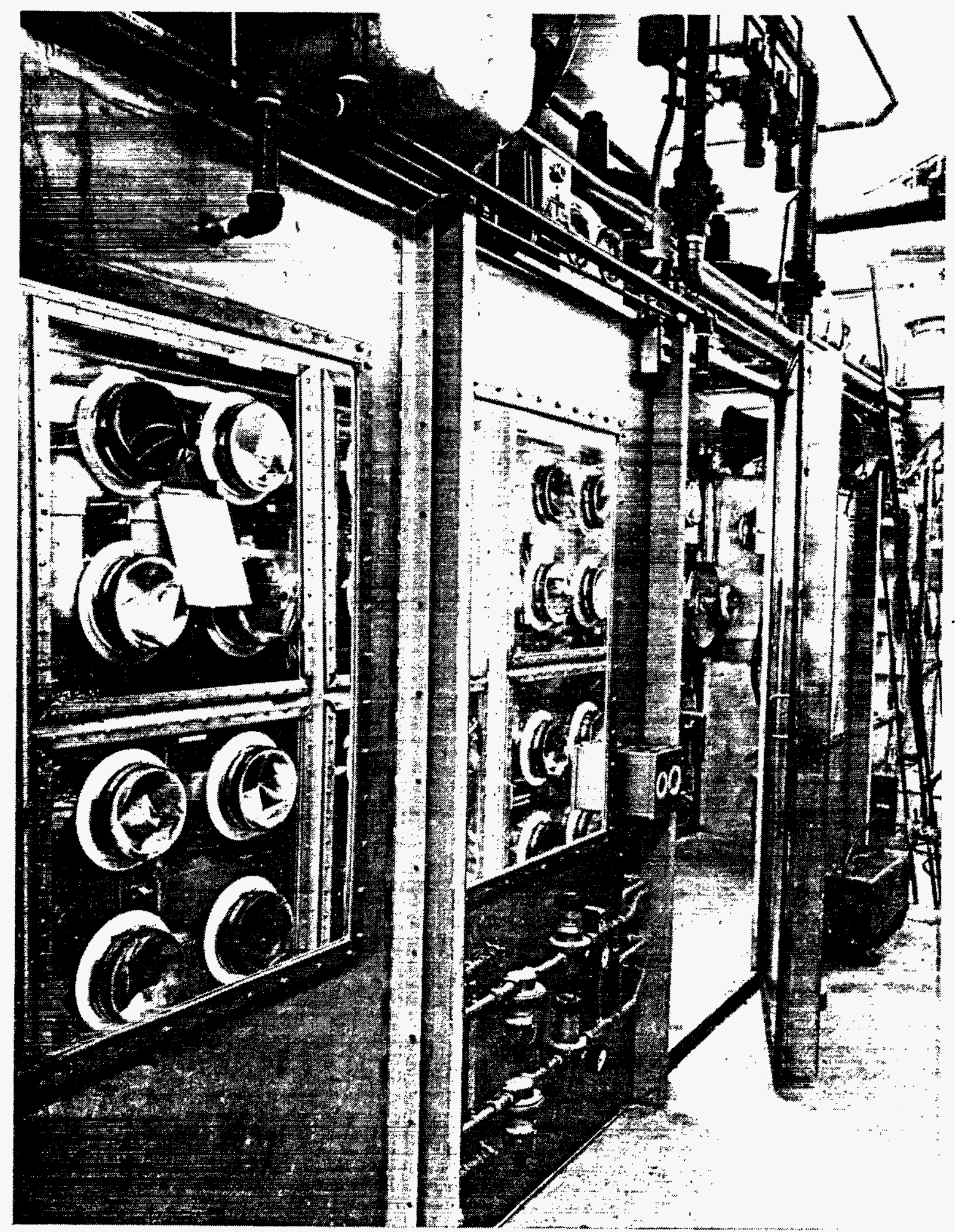

Figure 3-6 Photograph of Maintenance Hood 


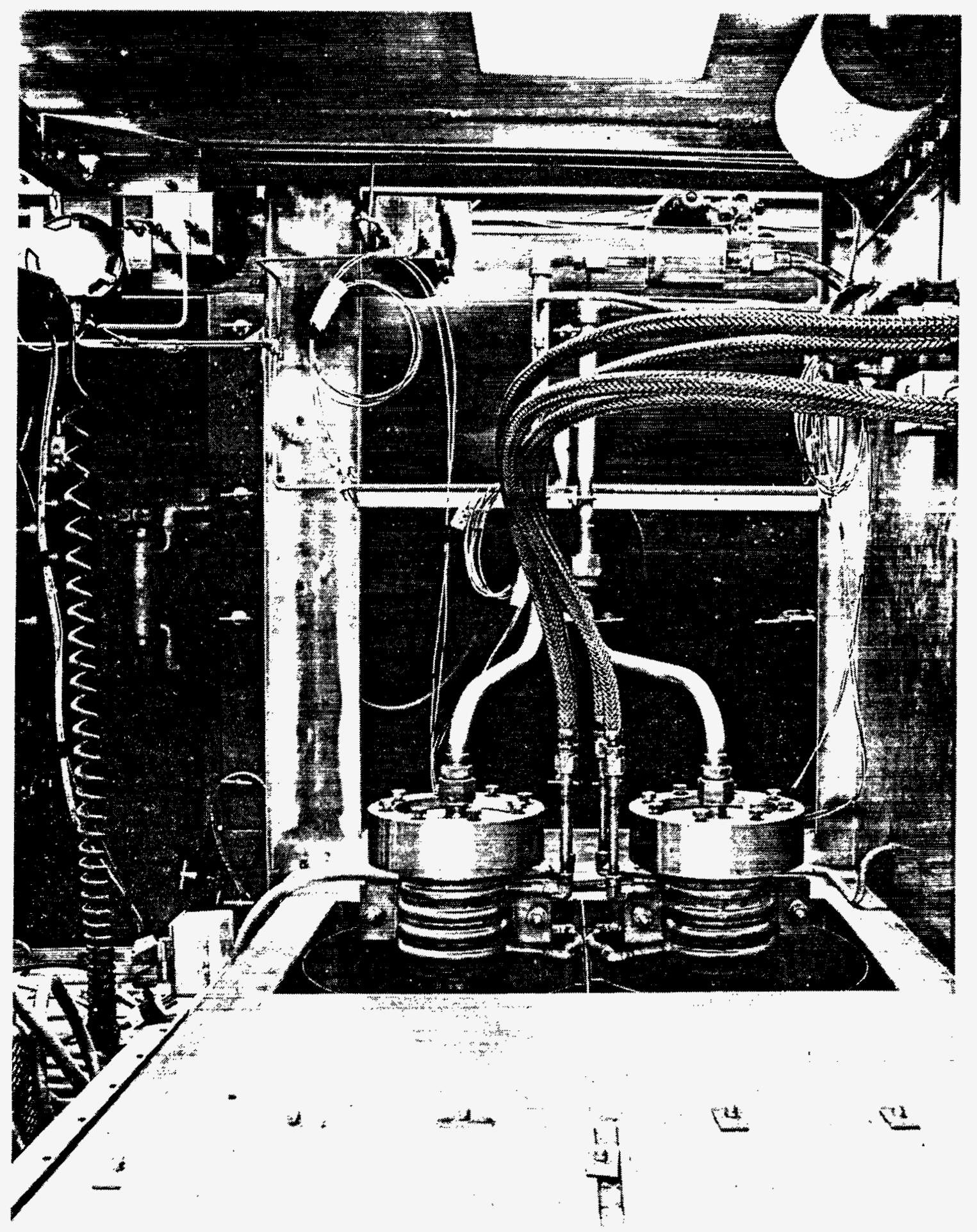

Figure 3-7 Photograph of Reactors Inside Inert Glovebox 


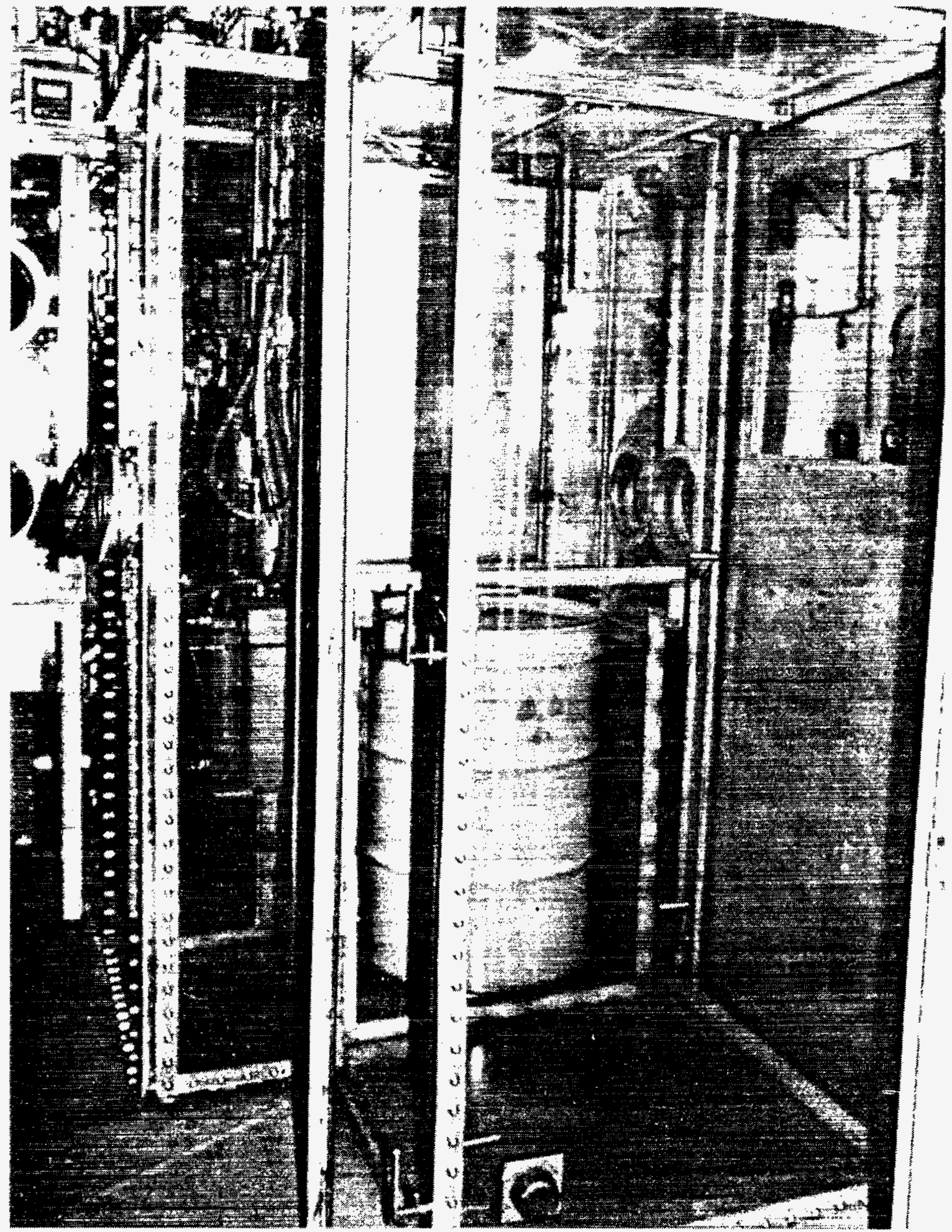

Figure 3-8 Photograph of Drumming Hood 


\section{DESCRIPTION OF OPERATIONS}

In the facility gaseous tritium is recovered from solid and gaseous scrap generated by Mound weapon development and production programs and from other DOE sites. The tritium and other hyarogen isotopes are purified by cryogenic adsorption.

Waste materials generally fall into the following general categories: lithium deuteride-tritide, calcium deuteride-tritide, titanium tritide scrap sources, reactor crucibles (stainless steel), drybox filters and other trash, tritium contaminated Helium-3 gas; tritium gas contaminated with air, argon and other impurities.

All solids are received and stored in welded stainless steel containers, sealed glass ampoules or o-ring sealed aluminum containers.

All gases are received and stored in calibrated stainless steel or mild steel containers.

An in-line calorimeter is used to assay most solid scrap materials. Sometimes it is necessary to repackage the solids inside the inert atmosphere drybox, remove the sealed container from the glovebox and calorimeter. Gases are measured by pressure and temperature in a known volume tank, and analyzed by mass spectrometry.

The solid scrap materials are loaded into a stainless steel reactor inside the inert atmosphere glovebox, along with a suitable reactant material (lead or mercury). The reactor is sealed and the temperature gradually raised to drive off the hydrogen isotope. The evolved gases are passed through stainless steel lines into the adjoining Process Hood.

The purification system has the gases purified by a 3 foot cold trap and then the remaining impurities adsorped on molecular sieve inside stainless steel traps which are cooled externally. The hydrogen isotopes are pumped into stainless steel holding tanks for analysis, and storage. The hydrogen isotopes may be further purified by adsorption on activated uranium. Desorption is accomplished by heating the inner container (which contains the activated uranium), while maintaining a vacuum between the inner and outer container. The purified hydrogen isotopes are then pumped to the thermal diffusion columns, located in the SW-Bldg., which produces an enriched tritium product. 


\section{ACCIDENT ANALYSIS}

\subsection{Introduction}

The purpose of this section is to identify, assess, and document the potential consequences of postulated accidents which could occur as a result of operations conducted in the R-108 facility. Two major categories of accidents are addressed: operational types and those caused by natural phenomenon.

\subsection{Operational Accidents}

Three major categories of accidents were considered for this analysis. The accidents addressed are: Fire, Explosion and Power Loss. Nuclear criticality is not a possibility for fissionable materials are not involved.

\subsubsection{Fire - Design Basis Accident}

There exist a potential for a fire in R-108 because operations will require the handling of tritium, pyrophoric metal hydrides and general combustibles found in laboratory types of operations. Extensive fire protection systems have been incorporated in the design of this facility to detect, limit and mitigate the consequences of a fire. The facility is completely sprinklered and is compatible with the requirements of The National Fire protection Association for ordinary hazard type of operations. Sprinkler systems have also been installed in air atmosphere type of enclosures such as sound enclosures and a maintenance hood. Essentially all the major operations will be conducted in stainless steel gloveboxes with an inert atmosphere to prevent the ignition of any materials handled. These enclosures are provided where the materials handled could result in personnel exposures and environmental impact. In addition to the automatic fire protection systems, Mound Facility has its own professional fire fighting force. Four-men crews work a 24-hour on and 48-hour off schedule. The Fire Department has equipment such as ambulance, a $750 \mathrm{gal} / \mathrm{min}$. high pressure/volume Class A pumper, a $13,500 \mathrm{ft}^{3} \mathrm{~min}$ "Hi-X" foam truck, etc. to fight a fire at Mound Facility. Response time after initiation of an alarm is estimated to be less than five minutes. Mound Facility can also call upon outside resources such as the City of Miamisburg in the remote event a fire developed to a major magnitude.

For the purpose of this analysis, the following series of events are postulated. A fire is initiated in a trash container as a result of a discarded cigarette or hot metal piece from a welding or cutting operation. Both actions would be a violation of established operating procedures. The fire then grows, undetected, to a point where it involves a set of glovebox gloves. Figure 3-5 shows the number of gloves in the facility and it can be seen that a fire involving a glove is a credible event. If the fire continues undetected, and without activating the sprinkler system, the glovebox would finally be breached and allow oxygen to enter. Initially there would be a surge of air entering the glovebox because of the slight negative pressure maintained in the gloveboxes are maintained at in comparison to the room. The breach of a glove would not result in 
the immediate establishment of an atmosphere that would support combustion. The in-leakage of oxygen and the outleakage of tritium would be mainly driven by a diffusion process. The purification system would continue to operate removing oxygen and water vapor and return a pure inert atmosphere.

The operating procedure requires that all metal tritides be in sealed containers when not being handled.

However, for the purpose of this analysis, it is assumed that a container of uranium tritide is open and sufficient oxygen is available to initiate the pyrophoric material. It is assumed that $10 \mathrm{grams}$ or 100,000 curies is released as HTO. The average concentration at the point of release would be $2.5 \times 10^{-1} \mathrm{uCi} / \mathrm{cc}$ if the incident occurred over two hours. It is considered incredible that operating personnel would be in the area without taking some action to stop the postulated series of events and, therefore, no personnel exposures are presented. The downwind concentration of HTO at d-max. would average $4.2 \times 10^{-4}$ $\mathrm{uCi} / \mathrm{CC}$ or 2000 times the RCG for a member of the general public. The resultant dose to an individual who remained at d-max. for the two-hour period would be 0.2 rem or 40 percent of the DOE's standards for normal operating modes. The potential exposure would be less than one percent of the guidelines stated in 10 CFR Part 100 for major accidents. No long term impact requiring actions such as decontamination would result to the environment.

The preceding scenerio is considered to be an event which would result in an upper limit of potential adverse impact to the environment and members of the general public. For this reason, it is also considered the Design Basis Accident for the Tritiated Scrap Recovery Facility.

\subsubsection{Explosion}

Tritium being an isotope of hydrogen displays many of the same characteristics as hydrogen, such as the ability to form an explosive mixture with air when present in the 4-93 percent range. The enclosures where gaseous hydrogen isotopes will be stored and handled will have inert atmospheres to preclude a hydrogen explosion. The inert atmosphere will be monitored for tritium and oxygen concentrations thereby giving operating personnel information regarding the potential for explosions as well as the existing radiological conditions. The ability of the tritium monitors to detect an increase in concentration is significantly more sensitive than a standard hydrogen analyzer. A monitor can detect an increase of 1 part per billion as compared to 4 parts per 100 need for an explosive mixture. The tritium monitors are designed to activate a high flow purge system at 100 parts per billion, thereby flushing the glovebox line of tritium and replacing the atmosphere with pure nitrogen. The total inventory of tritium in the glovebox system will not be capable of forming an explosive atmosphere in the glovebos line system. The potential for a hydrogen explosion is considered to be an incredible event. 
Most operations will be done in glovebox enclosures. Services such as helium to operate valves, nitrogen purge gas, etc. will enter the gloveboxes at.pressures in the 100 psig range. These services could provide a mechanism by which the gloveboxes could be pressurized to a degree where hood fronts and/or gloves could be blown off the glovebox line. Hence, services with this potential have been provided with limiting orifices to limit flow rate. The gloveboxes have a pressure differential control system and an independent backup system. In the event both control systems fail a passive relief system, (oil bubbler system) has been provided. This system would relieve a pressure buildup by venting the glovebox and, thereby avoiding breaching the glovebox. The potential for this type of accident is considered to be of low probability.

\subsubsection{Power Loss}

The equipment requiring electrical power is designed such that in the event of loss of electrical power, the systems will fail in a safe configuration. The ventilation system and the tritium effluent monitoring system have backup emergency power available from diesel generators and, therefore, would remain operational. The ERS does not have emergency power but there is a $1600 \mathrm{ft}^{3}$ holding tank to receive process gases for future processing. The major problem that could be encountered would be the buildup of HTO from inleakage of oxygen into the glovebox. This HTO would diffuse into the room, and, therefore, increase the chance of some personnel exposures and increased effluent releases if the power loss was for an extended time. Both incidents would be minor in nature based upon past experience with infrequent power losses for a few hours.

\subsection{Natural Phenomenon}

Two major types of natural phenomenon are addressed in this Appraisal, earthquakes and tornados. Events such as hurricanes and floods are not credible for the Mound Facility site. Realistically, the immediate risk to a member of the general public would be from the natural phenomenon itself and not that from the tritium in the $\mathrm{R}-108$ operations.

\subsubsection{Earthquake}

Mound's "Structural Evaluation of Mound Lab Buildings Under Tornado and Earthquake Conditions", dated July 1974, by Monsanto Corporate Engineering, Report \#CED 165, contains an earthquake analysis of $R$ Building.

In CED \#165, $R$ Bldg. is analyzed when subjected to an earthquake response spectra having a maximum horizontal ground acceleration of 108 gravity (g). The May 10, 1979 Dames \& Moore (D\&M) "Seismic Risk Evaluation, Mound Facility", recommends a $10 \% \mathrm{~g}$ level for the upper design level which would have 108 probability of being exceeded in 50 years. 
A comparison of CED \#165 and D\&M response spectra shows that the CED \#165 spectra is conservative (imparts more energy to the building). Therefore, the CED \#165 analysis of $\mathrm{R}$ Bldg. responding to the $108 \mathrm{~g}$ earthquake (labeled operating Basis Earthquake in that report) is used herein.

The R Bldg. will withstand the Design Basis Earthquake (DBE) (108 gravity, horizontal) with no impairment of its structural integrity. Some cracking will occur around openings in walls perpendicular to the direction of vibratory ground motion. Damage to the roof membranes will occur at the juncture of building additions with the original building and between the adjacent buildings. Should a nearby masonry chimney stack fall onto the building, it will cause severe damage to the metal-panel addition but little damage to the original building in which the facility will be located.

Cracking will occur around openings and at the bottom corners of walls perpendicular to the direction of vibratory ground motion. Cracks will originate at the corners of openings and progress upward and away from the opening. Horizontal cracks will occur directly above grade beams and spandrel beams near corners of walls perpendicular to the ground motion. The north and south walls of the original building and penthouse will experience the most cracking. Masonry cracks will penetrate the wall due to the reversal of stress in the wall.

The roofs of the building additions will experience some local yielding where they meet the original building. This yielding will be localized and will not result in any structural failures. Roof membranes, however, will be damaged as a result of the yielding. Coping stones not securely grouted to the parapet wall of the original building will be hurled from the building.

The masonry chimney stack located near the southwest corner of $R$ Bldg. will be toppled by the DBE, possibly landing on the building. However, this toppled stack is too far from $R-108$ to damage the facility.

\section{3 .2 Tornado}

In September of 1978, Mound Facility received a report from Dr. T. Theodore Fujita, Chicago, Illinois on "Tornado and High Wind Risks at MRC, Miamisburg, Ohio." This report was based on accepted, current, statistical risk analysis for tornadoes and high winds at Mound. The study summarized in the report is site specific. The report represents what Mound feels is a state-of-the-art study of our risks due to winds and tornadoes.

Dr. Fujita recommends that most buildings at the Monsanto (Miamisburg) site be designed to withstand winds/tornado that have a probability of recurrence of $10^{-4}$ years (once every 10,000 years). That event is a $115 \mathrm{mph}$ wind. However, Mound's Safety and Loss Prevention specialists have concluded that plutonium facilities should be designed to withstand a $10^{-6}$ year, event. This is a tornado having a maximum total wind speed of $234 \mathrm{mph}$. 
The facility recommended herein is neither a "standard low risk facility;" nor is it a plutonium processing facility. Therefore, the facility should be analyzed for $10^{-5}$ year event. A $10^{-5}$ year event (per Fujita) is a tornado with a maximum total windspeed of $179 \mathrm{mph}$. The CED \#165 analysis of $R$ Bldg. presents an analysis of a direct hit by a tornado having a maximum total windspeed of 200 mph. This was labelled a moderate tornado. The tornado damage analysis presented below is based on CED \#165 direct hit by a moderate tornado. This is conservative because the $180 \mathrm{mph}$ design tornado would be "20 mph less destructive".

Most of the building will survive a direct hit by a moderate tornado. Only the metal-panel wall addition south of column line 1 will be destroyed by the moderate tornado. Column lines are shown in Figure 3-2. This area is over $150 \mathrm{ft}$. south and east of the project site. Considerable cracking and some spalling a nd yielding will occur in the metal addition, but no structural failures will result. The timber missile will penetrate the building provided its direction of travel is parallel to the timber length and perpendicular to the wall surface hit. The exterior doors will be burst outward by the sudden pressure drop. The building is vented when the doors burst open, thus preventing the full pressure differential from being applied to the building structure. It should be noted that the full pressure differential would burst the roofs and original penthouse walls.

The original penthouse walls, especially the north and south walls, will experience considerable cracking under a direct hit by a moderate tornado. Horizontal cracks will develop between columns on the inside of the windward wall directly above the low roof and below the high roof spandrel beams. Similar cracking will occur on the inside of the leeward wall. Diagonal cracks will develop at the corners of the penthouse and around door openings. Vertical cracks will develop on the inside of the masonry walls at the junction of the leeward and side walls. All cracks in the windward wall will penetrate the wall due to the reversal of the stress in the wall. Should the north and south walls of the penthouse be parallel to the wind direction, diagonal tension cracks will originate at the corners of door openings and progress upward and toward the windward wall, or down and away from the windward wall. These diagonal tension cracks will also penetrate the building wall.

Portions of the north and south exterior walls of the first level will experience some cracking, especially if they become the windward and leeward walls. Horizontal cracking will occur directly above the grade beams and directly below the roof spandrel beams. Most of the east and west walls of the building will remain uncracked due to the shielding provided by $S W B I d g$. on the east side and E Bldg. on the west side.

Considerable cracking and some spalling will occur in roof slabs and framing due to the suction produced by the wind velocity. The original penthouse roof slab will develop cracks in the north-south direction between column lines $L$, $K$ and $J, H$. East-west cracks will develop between the numbered building column lines along the lettered column lines. These cracks will be most severe along column lines $\mathrm{K}$ and $\mathrm{J}$, and near the corners of the penthouse roof. In addition to these cracks in the roof slab, the roof spandrel beams at the corners of the windward wall will experience some spalling between columns. None of the roof cracking is expected to penetrate the roof slab. 
The low roof slab will develop east-west cracks above Rooms R-168, R-169 and R-169B. East-west cracks will also develop between the numbered column 1 ines along column lines $M$ and $G$. North-sout cracks will develop between $I$ ines $M$, $L$ and $H, G$. Some spalling of the spandrel beams near the corners of the windward wall may occur between building columns.

The metal panel wall addition south of column line 1 will be destroyed by the moderate tornado. The windward wall will buckle inward, opening up the wall at joints and corners. Panels on the leeward and side walls will buckle and be pulled free at their supporting girts. These panels will be blown away. Anchor bolts holding the center building columns to their foundations will fail and the entire roof system will be peeled from the building and be destroyed. Without the diaphragm action of the roof and sidewalls, the windward wall framing supporting the buckled wall panels will fold into the building. Smaller overall size and an intermediate girt prevent collapse of the metal-wall penthouse above Rooms RE-1 and RE-13.

Metal roof decks near the windward walls of the building will experience some yielding. The yielding will produce damage to the roof membrane. some yielding will also occur in the metal-wall penthouse wall panels at the intermediate girt.

The steel vent stack above Room SW-213 will be toppled by the moderate tornado, possibly landing on R-Bldg. Should the stack impact a masonry parapet wall, the portion of the parapet directly under the point of impact will be destroyed and some cracking of the bond beam and supporting masonry may occur. Should the stack impact the roof of the original portion of the buildings, no structural damage will occur. Should a metal deck roof be hit, local yielding of the roof deck will occur but the stack will not penetrate the roof into the building. The masonry chimneys located near R-Bldg. will withstand the moderate tornado.

Should the timber missile strike head-on into the masonry walls or concrete roof slabs, it will penetrate through the wall. At the point of impact, the concrete or masonry will explode into the building forming a funnel-shaped hole larger on the inside than on the outside. Reinforcing rods through the area will be exposed and badly twisted, possibly broken.

None of the structural damages, described above, will create missiles in R-108, the proposed project site. It is postulated that the lath and plaster room (R-108) may crack at the joints between the room walls and the room roof (crawlspace floor). It is further postulated that if the full vacuum can be drawn in R-l0B, the gloveboxes will stress heavily, but probably not fail because the gloves should expand creating additional volume and the bubblers blow out relieving the high differential pressure. 
Even if the gloveboxes failed, the process systems anticipated to remain intact and, therefore, it is not probable that there will be a major release of radioactive materials.

It is very important to realize that R-108 has a former R-Bldg. exterior wall on its west side. This very substantial wall is backed by the $S W B l d g$. Overhead there is a 6'3" crawlspace, capped with a heavily reinforced $21 / 2$ " thick concrete slab. Therefore, it is not probable that any tornado created missile can penetrate into, or be created in R-108 by the design base tornado. 


\section{CONCLUS IONS}

The operation of the Tritiated Scrap Recovery Facility will not pose a risk greater than is currently accepted from similar types of operations at Mound Facility. The overall risk of operation is considered to be low based upon the Qualitative Accident Severity and Probability categories as presented in DOE order 5481.1. The facility has also incorporated numerous design characteristics that will be consistent with the "As Low as Reasonably Achievable" (ALARA) philosophy. 